\title{
Raman Spectra and Vibrational Assignments for 1,1,1-Trihaloethanes and Their Deuterium Derivatives
}

\author{
Thomas R. Stengle ${ }^{1}$ and Robert Cooper Taylor
}

Department of Chemistry, The University of Michigan, Ann Arbor, Michigan 48104

\begin{abstract}
Raman spectra of the first three members of the 1,1,1-trihaloethane series, $\mathrm{CH}_{3} \mathrm{CX}_{3}, \mathrm{X}=\mathrm{F}, \mathrm{Cl}, \mathrm{Br}$, were obtained for the liquids under low resolution. All but two active fundamental vibrational frequencies were observed, and for most bands it was possible to make a qualitative determination of the depolarization ratio. The completely deuterated compounds were synthesized and their spectra also were examined. Normal coordinate calculations were carried out to confirm the proposed assignments.
\end{abstract}

\section{INTRODUCTION}

Vibrational spectra of only two 1,1,1-trihaloethanes have been reported in the literature. The fluorine compound, $\mathrm{CH}_{3} \mathrm{CF}_{3}$, has been studied by a number of investigators (1-5) with general agreement in assignments except for the two $\mathrm{CF}_{3}$ deformation modes where uncertainty as to symmetry species exists. The only reference to the deuterated variety is in a recent article by Lafon and Nielsen (6) who cite values for the fundamentals based on data in a dissertation by Susi (7). No experimental details are given in Ref. $(6)$.

The infrared and Raman spectra of 1,1,1-trichloroethane have been reported by numerous workers and only the most recent articles are cited here (8-12). The assignments for this molecule were the subject of controversy for some time until Evans and Bernstein (12) resolved the remaining uncertainty with the help of the spectrum of the deuterated molecule. The assignments for this molecule appear well established.

Vibrational data for the little known compound 1,1,1-tribromoethane have never been reported.

The only recent normal coordinate analysis of these molecules is the treatment by Lafon and Nielsen $(6)$ of $\mathrm{CH}_{3} \mathrm{CF}_{3}$ and $\mathrm{CD}_{3} \mathrm{CF}_{3}$ using a Urey-Bradley potential function. Earlier calculations $(10,13)$ were based on incomplete data and also have been shown to contain errors $(6,14)$.

${ }^{1}$ Present address: Department of Chemistry, University of Massachusetts, Amherst, Massachusetts. 


\section{EXPERIMENTAL METHODS}

The 1,1,1-trifluoroethane was prepared by halogen exchange between $\mathrm{CH}_{3} \mathrm{CCl}_{3}$ and $\mathrm{SbF}_{3}$ using a small amount of $\mathrm{SbF}_{3} \mathrm{Cl}_{2}$ as a halogen carrier. 'The method was essentially that of Henne and Renoll (15). The product was purified by repeated bulb-to-bulb distillation until its infrared spectrum showed no further change. The deuterated fluoride was prepared in the same manner starting with $1,1,1$ trichloroethane- $d_{3}$.

The 1,1,1-trichloroethane was obtained from Distillation Products Industries, Inc., and distilled through a small fractionating column before use. Its spectrum was in good agreement with published records. The authors are indebted to Dr. I. C. Leitch of the Canadian National Research Council for an initial sample of $1,1,1$-trichloroethane- $d_{3}$. Additional material was prepared by a method similar to that of Francis and Leitch (16) using trichloroethylene as starting material.

The only synthesis of 1,1,1-tribromoethane found in the literature was based on a Wurtz reaction between $\mathrm{CH}_{3} \mathrm{Br}$ and $\mathrm{CBr}_{4}(17)$. Since this method gave poor yields of a product which was difficult to purify, a new and improved method was developed in the present work which is described as follows. Five ml of $\mathrm{CH}_{3} \mathrm{CCl}_{3}$ were dissolved in $250 \mathrm{ml}$ of carbon disulfide previously saturated with $\mathrm{HBr}$ at $0^{\circ} \mathrm{C}$. A solution of $4 \mathrm{~g}$ of anhydrous $\mathrm{AlBr}_{3}$, dissolved in $100 \mathrm{ml}$ of dry $\mathrm{CS}_{2}$ in a dropping funnel, was added dropwise to the $\mathrm{CH}_{3} \mathrm{CCl}_{3}$ solution over the course of an hour. During the addition, a slow stream of $\mathrm{HBr}$ was passed through the reaction mixture. To recover the product, the reaction mixture was extracted twice with ice water made basic with ammonium hydroxide. After drying, the solvent was distilled off and the residue was vacuum distilled (bp $60-70^{\circ} \mathrm{C}$ at $15 \mathrm{~mm} \mathrm{Hg}$ ). Further purification was carried out by repeated fractionation on the vacuum line, the final yield being about $50 \%$. The identity of the compound was established by its mass spectrum and chemical analysis for total halogen; calc for $\mathrm{Br}, 89.9 \%$; found, $89.8 \% .1,1,1$-Tribromoethane is a white solid with a melting point of $30^{\circ} \mathrm{C}$. It is decomposed by light when impure but the pure material is quite stable and remains colorless indefinitely when sealed off in glass in the absence of oxygen. The deuterated bromide was prepared in the same fashion starting with the deuterated chloride.

Samples for spectroscopic examination were prepared by distilling the compounds into capillary Raman tubes which were then sealed off under vacuum. The spectrograph and light source have been described previously (18). Spectra were obtained with the samples in the liquid state, the temperatures being $0^{\circ}$ for the fluoride, $25^{\circ}$ for the chloride and $40^{\circ}$ for the bromide. Qualitative estimates of the depolarization ratios were obtained using the two-exposure method and polarizing the incident light with Polaroid cylinders. Several plates were taken for each compound and measurements were made both on plates and on 


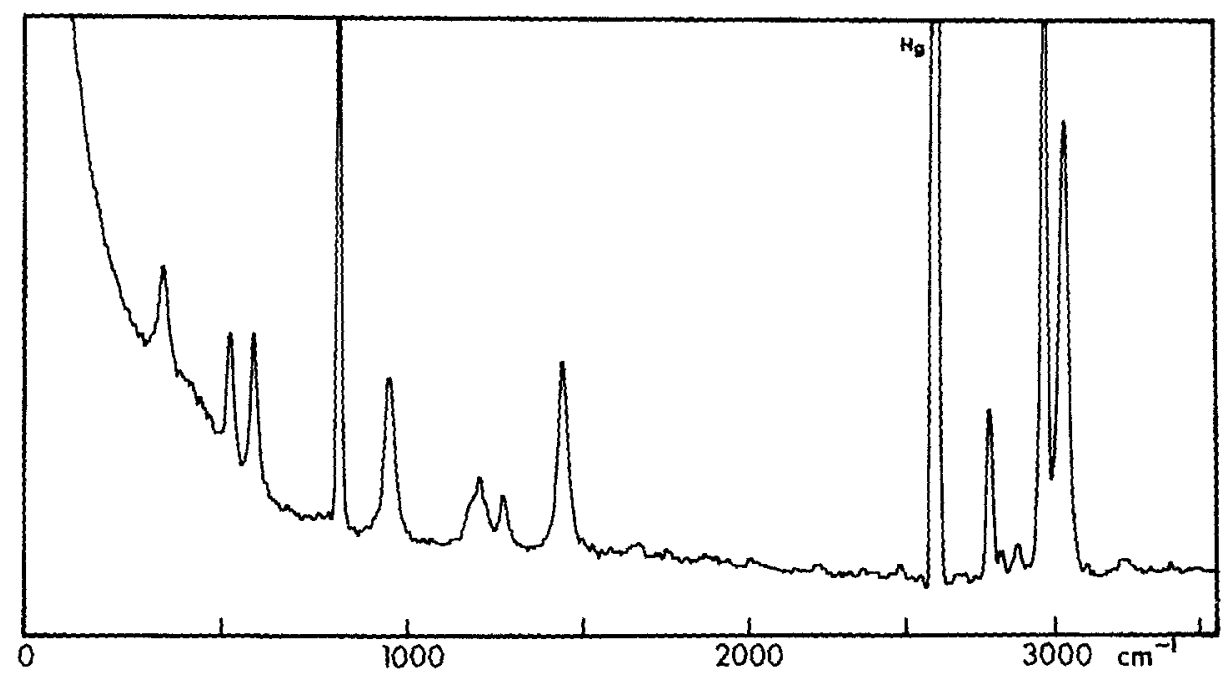

Fig. 1. Ramsn spectrum of liquid $\mathrm{CH}_{3} \mathrm{CF}_{8}$ at $0^{\circ} \mathrm{C}$

microphotometer tracings. The data tabulated represent weighted averages of all measurements for a particular compound.

\section{EXPERIMENTAL RESULTS AND ASSIGNMENTS}

Apparently the only one of these molecules for which a fully determined structure has been published is the fluoro compound $(19,20)$. However, there seems little doubt that the $\mathrm{CH}_{3} \mathrm{CX}_{3}$ molecules have $C_{3 v}$ symmetry with a staggered configuration. This model predicts 12 fundamental frequencies with the distribution $5 A_{1}+A_{2}+6 E$, the $A_{2}$ frequency being both Raman and infrared inactive. The numbering scheme and approximate description of fundamentals for all three molecules follows that used previously for $\mathrm{CH}_{3} \mathrm{CCl}_{3}$ (8). Although as a result the numbering of some of the $\mathrm{CH}_{3} \mathrm{CF}_{3}$ fundamentals becomes inconsistent with previous work and the usual conventions, the series itself is internally consistent.

1,1,1-Trifluoroethane. Microphotometer tracings of the Raman spectra of 1,1,1-trifluoroethane and its deuterated derivative are shown in Figs. 1 and 2 while the observed Raman fundamentals are listed in Tables I and II. Assignments and frequency values for both compounds agree with those given by Nielsen (6) and Susi (7). A few of the bands appear to be sensitive to physical state, for example the bands near $800 \mathrm{~cm}^{-1}$ where the Raman (liquid) and infrared (gas) values differ somewhat. In the early work on $\mathrm{CH}_{3} \mathrm{CF}_{3}(4,5)$, disagreement existed as to the relative assignment of the two $\mathrm{CF}_{3}$ deformation modes since the depolarization ratios of the two bands are about the same. The present work on the deuterated compound shows that the higher of the 


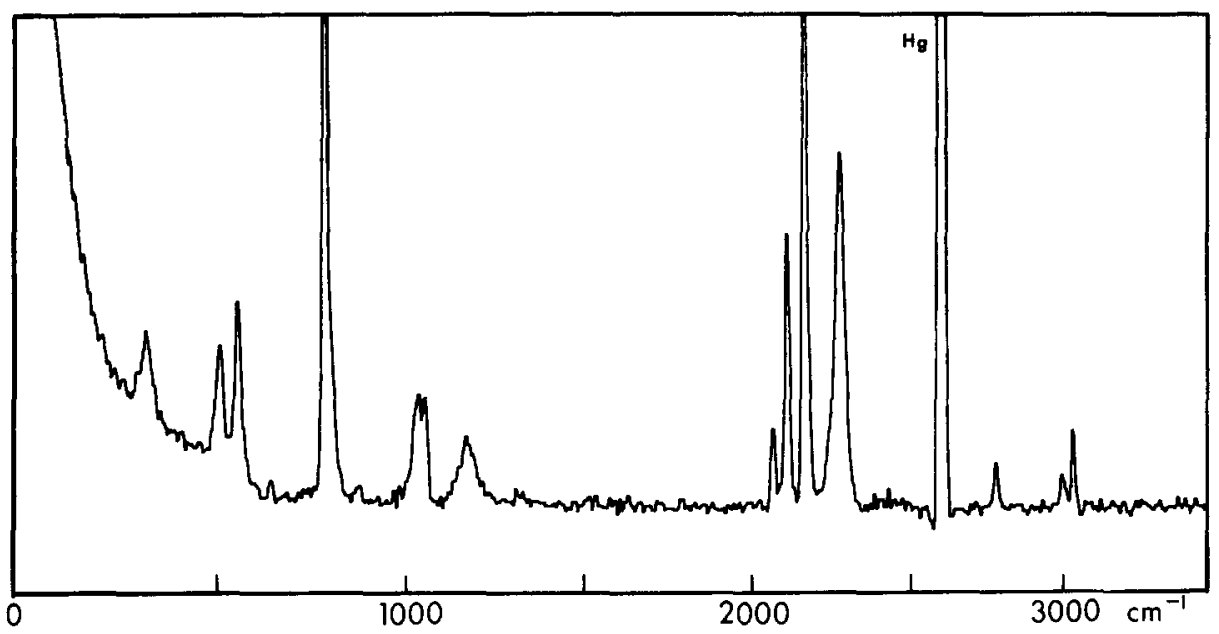

Fig. 2. Raman spectrum of liquid $\mathrm{CD}_{3} \mathrm{CF}_{3}$ at $0^{\circ} \mathrm{C}$

TABLE I

Observed and Calculated Fundamental Frequencies for $\mathrm{CH}_{3} \mathrm{CX}_{3}$ Molegules $(\mathrm{X}=\mathrm{F}, \mathrm{Cl}, \mathrm{Br})\left(\right.$ in $\left.\mathrm{cm}^{-1}\right)$

\begin{tabular}{|c|c|c|c|c|c|c|c|c|c|}
\hline \multirow{2}{*}{$\begin{array}{l}\text { Freq. no. } \\
\text { and } \\
\text { descript. }\end{array}$} & \multicolumn{3}{|c|}{$\mathrm{CH}_{3} \mathrm{CF}_{3}$} & \multicolumn{3}{|c|}{$\mathrm{CH}_{3} \mathrm{CCl}_{3}$} & \multicolumn{3}{|c|}{$\mathrm{CH}_{3} \mathrm{CBr}_{3}$} \\
\hline & Obs & Calc & $\Delta$ & Obs & Calc & $\Delta$ & Obs & Calc & $\Delta$ \\
\hline$A_{1}$ Class & & & & & & & & & \\
\hline$\nu_{1} \nu \mathrm{C}-\mathrm{H}$ & 2970 & 2971 & -1 & 2943 & 2943 & 0 & 2938 & 2938 & 0 \\
\hline$\nu_{2} \delta \mathrm{CH}_{3}$ & 1408 & 1410 & -2 & 1384 & 1384 & 0 & 1373 & 1373 & 0 \\
\hline$\nu_{3} \nu \mathrm{C}-\mathrm{C}$ & 827 & 829 & -2 & 1071 & 1071 & 0 & 1045 & 1015 & 0 \\
\hline$\nu_{4} \nu \mathrm{C}-\mathrm{X}$ & 1282 & 1285 & -3 & 525 & 526 & -1 & 408 & 407 & 1 \\
\hline $\begin{array}{ll}\nu_{5} \quad \delta \mathrm{CX}_{3} \\
E \text { Class }\end{array}$ & 600 & 602 & -2 & 343 & 342 & 1 & 211 & 211 & 0 \\
\hline$\nu_{7} \nu \mathrm{C}-\mathrm{H}$ & 3038 & 3041 & -3 & 3009 & 3011 & -2 & 2993 & 2994 & -1 \\
\hline$\nu_{8} \delta \mathrm{CH}_{3}$ & 1452 & 1452 & -1 & 1444 & 1450 & -6 & 1432 & 1434 & -2 \\
\hline$\nu_{9} \rho \mathrm{CH}_{3}$ & 963 & 962 & 1 & 1079 & 1079 & 0 & 1064 & 1060 & 4 \\
\hline$\nu_{10} \nu \mathrm{C}-\mathrm{X}$ & 1214 & 1212 & 2 & 711 & 713 & 0 & 628 & 623 & 5 \\
\hline$\nu_{11} \delta \mathrm{CX}_{3}$ & 538 & 540 & -2 & 343 & 344 & -1 & 275 & 279 & -4 \\
\hline$\nu_{12} \rho \mathrm{CX}_{3}$ & 366 & 369 & -3 & 238 & 239 & -1 & 145 & 144 & 1 \\
\hline
\end{tabular}

two bands clearly is polarized and the lower is not giving an unequivocal assignment. Since it seems unlikely that the symmetric and asymmetric motions would interchange position upon deuteration, the evidence supports Nielsen's assignment of the higher band to the symmetric mode in $\mathrm{CH}_{3} \mathrm{CF}_{3}$.

In the case of $\mathrm{CD}_{3} \mathrm{CF}_{3}$, only four clearly polarized bands of medium to high intensity were observed and the location of the fifth $A_{1}$ fundamental proved 
TABLE II

Observed and Calculated Fundamental Frequencias for $\mathrm{CD}_{3} \mathrm{CX}_{3}$ Molecules $(\mathrm{X}=\mathrm{F}, \mathrm{Cl}, \mathrm{Br})\left(\right.$ in $\left.\mathrm{cm}^{-1}\right)$

\begin{tabular}{|c|c|c|c|c|c|c|c|c|c|}
\hline \multirow{2}{*}{$\begin{array}{l}\text { Freq. no. } \\
\text { and } \\
\text { descript. }\end{array}$} & \multicolumn{3}{|c|}{$\mathrm{CD}_{3} \mathrm{CF}_{3}$} & \multicolumn{3}{|c|}{$\mathrm{CD}_{3} \mathrm{CCl}_{3}$} & \multicolumn{3}{|c|}{$\mathrm{CD}_{3} \mathrm{CBr}_{3}$} \\
\hline & Obs. & Calc. & $\Delta$ & Obs. & Calc. & $\Delta$ & Obs. & Calc. & $\Delta$ \\
\hline$A_{1}$ Class & & & & & & & & & \\
\hline$\nu_{1} \nu \mathrm{C}-\mathrm{D}$ & 2170 & 2169 & 1 & 2130 & 2130 & 0 & 2116 & 2116 & 0 \\
\hline$\nu_{2} \delta \mathrm{CD}_{3}$ & 1065 & 1062 & 3 & 1142 & 1142 & 0 & 1110 & 1110 & 0 \\
\hline$\nu_{3} \nu \mathrm{C}-\mathrm{C}$ & 798 & 795 & 3 & 975 & 975 & 0 & 953 & 953 & 0 \\
\hline$\nu_{4} \nu \mathrm{C}-\mathrm{X}$ & 1322 & 1320 & 2 & 504 & 503 & 1 & 388 & 389 & -1 \\
\hline $\begin{array}{l}\nu_{5} \delta \mathrm{CX}_{3} \\
E \text { Class }\end{array}$ & 568 & 566 & 2 & 332 & 333 & -1 & 209 & 210 & -1 \\
\hline$\nu_{7} \nu \mathrm{C}-\mathrm{D}$ & 2281 & 2277 & 4 & 2259 & 2256 & 3 & 2241 & 2239 & 2 \\
\hline$\nu_{8} \delta \mathrm{CD}_{3}$ & 1182 & 1184 & -2 & 1050 & 1042 & 8 & 1038 & 1035 & 3 \\
\hline$\nu_{9} \rho \mathrm{CD}_{3}$ & 820 & 822 & -2 & 914 & 915 & -1 & 883 & 887 & -4 \\
\hline$\nu_{10} \nu \mathrm{C}-\mathrm{X}$ & 1045 & 1043 & 2 & 654 & 654 & 0 & 583 & 589 & -6 \\
\hline$\nu_{11} \delta \mathrm{CX}_{3}$ & 522 & 524 & 3 & 316 & 315 & 1 & 244 & 240 & 4 \\
\hline$\nu_{12} \rho \mathrm{CX}_{3}$ & 332 & 328 & 4 & 231 & 230 & 1 & 142 & 142 & 0 \\
\hline
\end{tabular}

somewhat elusive. Application of the product rule (Table III) predicted that the missing band should be located around 1300 to $1350 \mathrm{~cm}^{-1}$. On long exposures, a weak band was finally observed in this region with its maximum at about $1322 \mathrm{~cm}^{-1}$ and this is assigned to the missing fundamental. Its polarization state could not be determined due to its low intensity but the product rule does not allow any other choice. Susi (7) states that the infrared intensity of this band is fairly high as is customarily observed in modes involving a $\mathrm{CF}_{3}$ group. The unexpectedly high frequency position is attributed to the influence of another $A_{1}$ fundamental nearby at $1065 \mathrm{~cm}^{-1}$; as might be expected, the normal coordinate calculations show that the $1322 \mathrm{~cm}^{-1}$ mode is strongly mixed.

A somewhat similar situation was found in the $E$ class frequencies of $\mathrm{CD}_{3} \mathrm{CF}_{3}$; examination of the spectrum yielded only five depolarized bands that could be readily assigned by comparison with the hydrogen compound. The missing frequency was $\nu_{9}$ which the product rule indicated should be found in the neighborhood of $850 \mathrm{~cm}^{-1}$. Careful inspection of the plates and tracings revealed a weak band nearly obscured by the strong peak due to an $A_{1}$ fundamental at $798 \mathrm{~cm}^{-1}$. This band, which is visible as a weak shoulder in the tracing of Fig. 2, is assigned to the missing fundamental. The estimated position of $820 \mathrm{~cm}^{-1}$ may be slightly high since Susi (7) gives values of 805 and $798 \mathrm{~cm}^{-1}$ for the $A_{1}$ and $E$ fundamentals, respectively.

$1,1,1$-Trichloroethane. The Raman spectra of the normal and deuterated compound were obtained in the present investigation largely as a matter of completeness and to provide comparison spectra. The assignment of fundamentals given by Fvans and Bernstein (12) was confirmed. Their explanation 


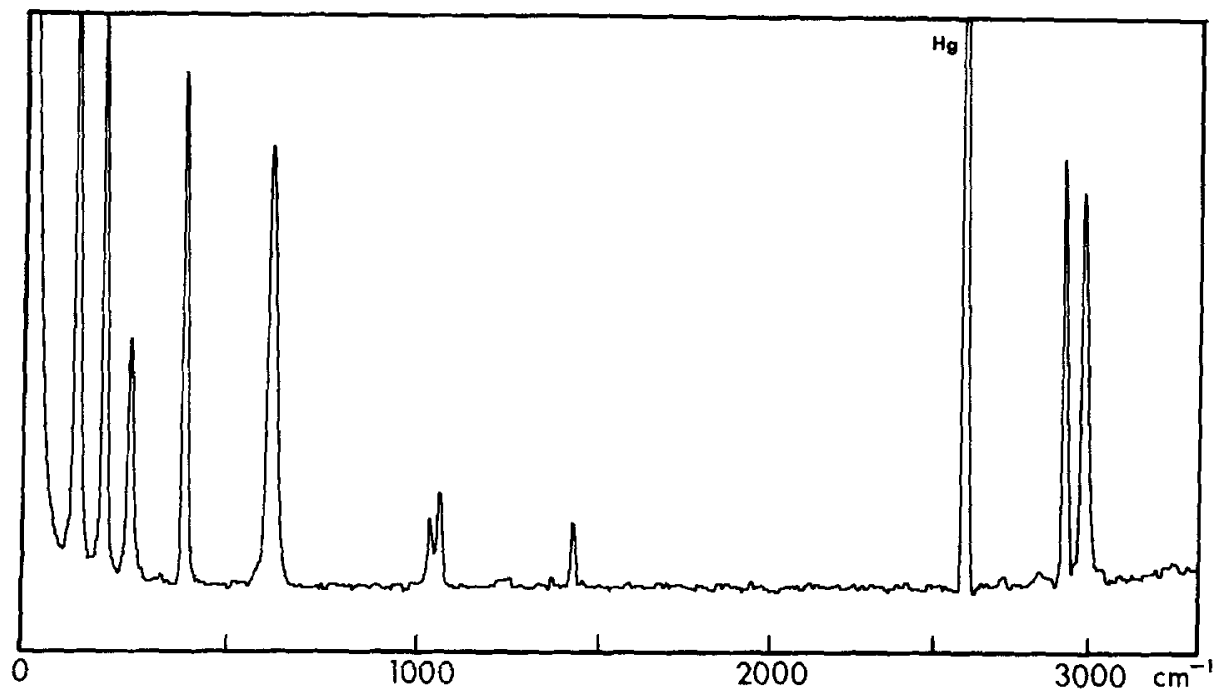

FIg. 3. Raman spectrum of liquid $\mathrm{CH}_{3} \mathrm{CBr}_{3}$ at $40^{\circ} \mathrm{C}$

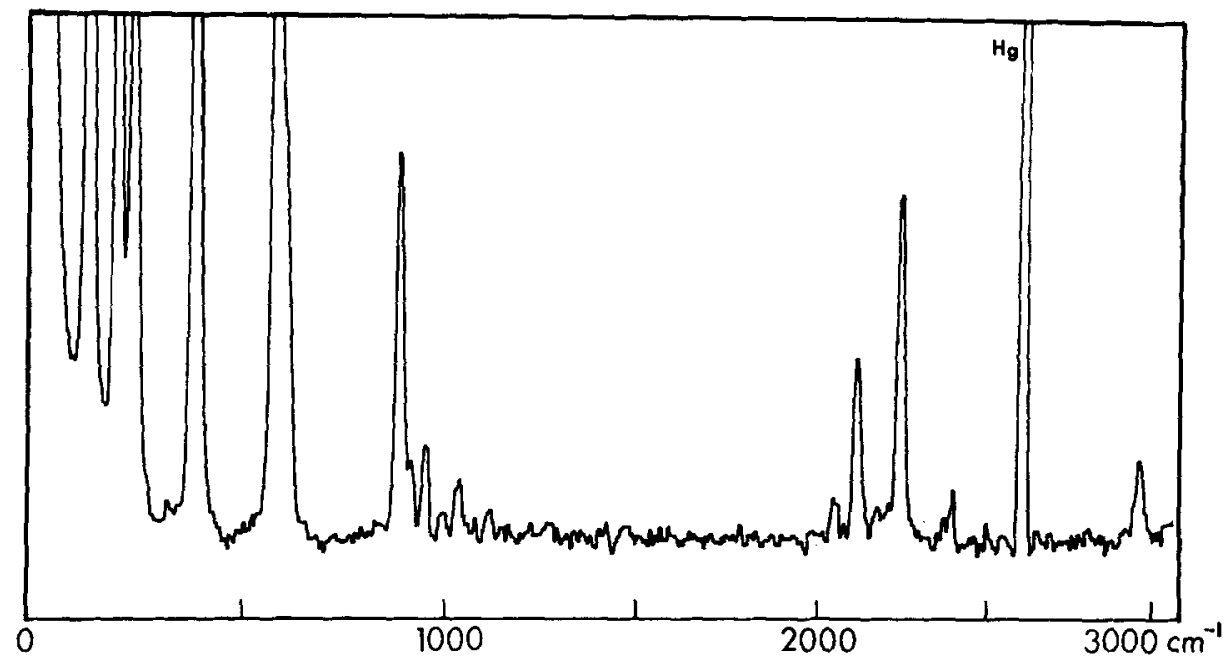

Fig. 4. Raman spectrum of liquid $\mathrm{CD}_{3} \mathrm{CBr}_{2}$ at $40^{\circ} \mathrm{C}$

of the apparent absence of $\nu_{11}$ as being due to an accidental degeneracy with $\nu_{5}$ not only agrees with the polarization results but also appears entirely consistent with the frequency pattern of the other two haloethanes (Fig. 5). The experimental results shown in Tables I and II agree well with literature values.

$1,1,1$-Tribromoethane. As was mentioned previously, this compound is so little known that many of its common physical properties are not listed in the 

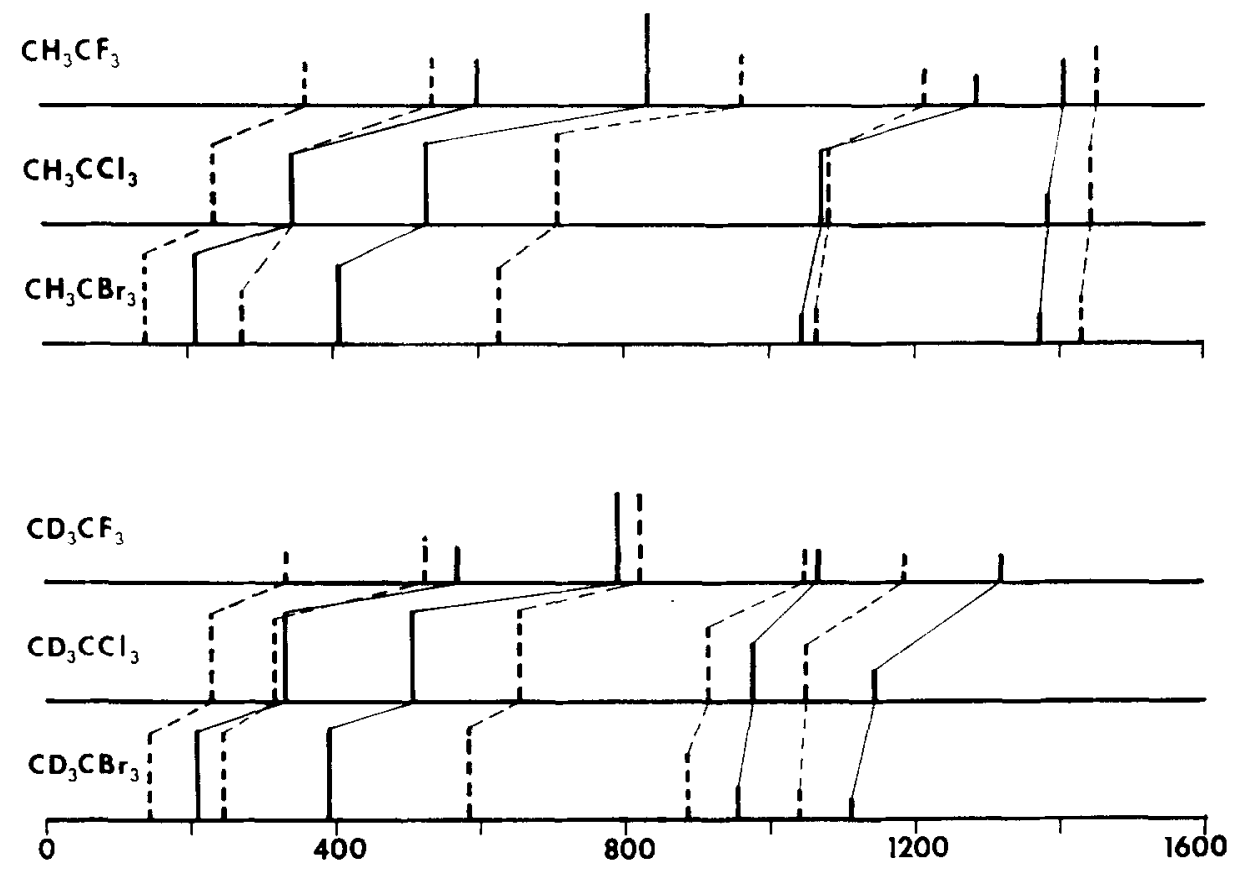

FIG. 5. Correlation diagrams for 1,1,1-trihaloethanes

literature. Few compounds containing a $\mathrm{CBr}_{3}$ group have been studied spectroscopically. The experimental values of the fundamentals for the two isotopic species are also given in Tables I and II and tracings of the spectra are shown in Figs. 3 and 4.

Assignments for the bromo compound followed in a straightforward fashion from those made for the fluoro and chloro compounds. In the case of $\mathrm{CH}_{3} \mathrm{CBr}_{3}$, four medium to strongly polarized lines were observed which could readily be assigned to four of the $A_{1}$ species. The fifth, the symmetric $\mathrm{CH}_{3}$ deformation $\nu_{2}$, was assigned to the band at $1373 \mathrm{~cm}^{-1}$ although it was sufficiently low in intensity that its polarization state could not be determined reliably. However, the assignment is consistent with those for other members of the series. The assignment of $\nu_{2}$ for the deuterated species was difficult since several lines clustered in the region around $1000 \mathrm{~cm}^{-1}$. Since most of these were weak, polarization results were not definitive. The most intense maximum at $1083 \mathrm{~cm}^{-1}$ appeared to be depolarized and consequently is assigned as the $E$ class deformation mode, $\nu_{8}$. Of the remaining two maxima, the one at $1002 \mathrm{~cm}^{-1}$ can be assigned to a combination band $(142+883=1025)$ leaving the band at $1110 \mathrm{~cm}^{-1}$ for the symmetric $\mathrm{CD}_{3}$ deformation, $\nu_{2}$. Although this assignment inverts the positions of $\nu_{2}$ and $\nu_{9}$ upon deuterium substitution, this is not disturbing since it also occurs 
TABLE III

Teller-Reduch Product Rule Ratios for Methyl Haloforms

\begin{tabular}{lccccc} 
& \multicolumn{2}{c}{$A_{1}$ Class } & & \multicolumn{2}{c}{$E$ Class } \\
\cline { 2 - 3 } \cline { 5 - 6 } & Theor. & Exptl. & & Theor. & Exptl. \\
\hline $\mathrm{CH}_{3} \mathrm{CF}_{3} / \mathrm{CD}_{3} \mathrm{CF}_{3}$ & 1.963 & 1.921 & 2.615 & 2.536 \\
$\mathrm{CH}_{3} \mathrm{CCl}_{3} / \mathrm{Cl}_{3} \mathrm{CCl}_{3}$ & 1.976 & 1.979 & 2.696 & 2.629 \\
$\mathrm{CH}_{3} \mathrm{CBr}_{3} / \mathrm{Cl}_{3} \mathrm{CBrr}_{3}$ & 1.987 & 1.999 & 2.756 & 2.752 \\
\hline
\end{tabular}

in the chloride where the assignments are well established. The proposed assignments give good agreement with the theoretical Teller-Redlich product rule ratios calculated from the determinants of the inverse kinetic energy $(G)$ matrices, as shown in Table III.

\section{NORMAL COORDINATE CALCULATIONS}

Normal coordinate calculations were performed on an IBM 7090 computer using an iterative least-squares procedure similar to that described by Overend and Scherer (21), Aldous and Mills (22), and others. Refinement was carried out in terms of symmetry force constants rather than on the basis of any more specialized force field. Data for both the hydrogen and deuterium species for a given halogen were fitted simultaneously and the deviation between observed and calculated frequencies were minimized using weighting factors proportional to the squared reciprocal frequency. Each symmetry class was treated separately. Since fewer frequencies were available than the number of force constants, it was necessary to constrain several constants. In general, the off-diagonal constants constrained either connected coordinates having no atoms in common, and therefore could be presumed to be quite small, or were found during the calculations to be relatively unimportant to the frequency fit. Only for the $A_{1}$ class of the fluoro and chloro conpounds was the number of force constants calculated equal to the number of frequencies observed; in all other cases, fewer constants than frequencies were required.

The symmetry coordinates employed are given below. The numbering scheme for the atoms is straightforward and is identical with one described adequately in the literature (29) for a $\mathrm{X}_{3} \mathrm{YZW}_{3}$ molecule and consequently a sketch is not reproduced here. The symmetry coordinate, $S_{6}$, which belongs to the $A_{2}$ class has been omitted since the frequency is inactive. $S_{01}$ and $S_{02}$ are redundant coordinates involving the angles around the two carbon atoms.

Molecular Geometry for $\mathrm{CH}_{3} \mathrm{CX}_{3}$ :

$$
\begin{aligned}
& r=\mathrm{C}-\mathrm{H}, \quad R=\mathrm{C}-\mathrm{C}, \quad d=\mathrm{C}-\mathrm{X}, \\
& \alpha=\mathrm{H}-\mathrm{C}-\mathrm{H} \text { angle, } \quad \gamma=\mathrm{X}-\mathrm{C}-\mathrm{X} \text { angle, } \\
& \beta=\mathrm{H}-\mathrm{C}-\mathrm{C} \text { angle }, \quad \delta=\mathrm{X}-\mathrm{C}-\mathrm{C} \text { angle. }
\end{aligned}
$$


$A_{1}$ Symmetry coordinates:

$$
\begin{aligned}
& S_{01}=1 / \sqrt{c_{1}}\left[\Delta \alpha_{1}+\Delta \alpha_{2}+\Delta \alpha_{3}+b_{1}\left(\Delta \beta_{1}+\Delta \beta_{2}+\Delta \beta_{3}\right)\right], \\
& S_{02}=1 / \sqrt{c_{3}}\left[\Delta \gamma_{1}+\Delta \gamma_{2}+\Delta \gamma_{3}+b_{3}\left(\Delta \delta_{1}+\Delta \delta_{2}+\Delta \delta_{3}\right)\right], \\
& S_{1}=1 / \sqrt{3}\left[\Delta r_{1}+\Delta \gamma_{2}+\Delta r_{3}\right], \\
& S_{2}=1 / \sqrt{c_{1}}\left[b_{1}\left(\Delta \alpha_{1}+\Delta \alpha_{2}+\Delta \alpha_{3}\right)-\left(\Delta \beta_{1}+\Delta \beta_{2}+\Delta \beta_{3}\right)\right] \\
& S_{3}=\Delta R, \\
& S_{4}=1 / \sqrt{3}\left[\Delta d_{1}+\Delta d_{2}+\Delta d_{3}\right], \\
& S_{5}=1 / \sqrt{c_{3}}\left[b_{3}\left(\Delta \gamma_{1}+\Delta \gamma_{2}+\Delta \gamma_{3}\right)-\left(\Delta \delta_{1}+\Delta \delta_{2}+\Delta \delta_{3}\right)\right] .
\end{aligned}
$$

E'Symmetry Coordinates:

$$
\begin{aligned}
& S_{7}^{\prime}=1 / \sqrt{2}\left[\Delta r_{2}-\Delta r_{3}\right], \\
& S_{7}^{\prime \prime}=1 / \sqrt{6}\left[2 \Delta r_{1}-\Delta r_{2}-\Delta r_{3}\right], \\
& S_{8}^{\prime}=1 / \sqrt{2}\left[\Delta \alpha_{2}-\Delta \alpha_{3}\right], \\
& S_{8}^{\prime \prime}=1 / \sqrt{6}\left[2 \Delta \alpha_{1}-\Delta \alpha_{2}-\Delta \alpha_{3}\right], \\
& S_{9}^{\prime}=1 / \sqrt{2}\left[\Delta \beta_{2}-\Delta \beta_{3}\right], \\
& S_{9}^{\prime \prime}=1 / \sqrt{6}\left[2 \Delta \beta_{1}-\Delta \beta_{2}-\Delta \beta_{3}\right], \\
& S_{10}^{\prime}=1 / \sqrt{2}\left[\Delta d_{2}-\Delta d_{3}\right], \\
& S_{10}^{\prime \prime}=1 / \sqrt{6}\left[2 \Delta d_{1}-\Delta d_{2}-\Delta d_{3}\right], \\
& S_{11}^{\prime}=1 / \sqrt{2}\left[\Delta \gamma_{2}-\Delta \gamma_{3}\right], \\
& S_{11}^{\prime \prime}=1 / \sqrt{6}\left[2 \Delta \gamma_{1}-\Delta \gamma_{2}-\Delta \gamma_{3}\right], \\
& S_{12}^{\prime}=1 / \sqrt{2}\left[\Delta \delta_{2}-\Delta \delta_{3}\right], \\
& S_{12}^{\prime \prime}=1 / \sqrt{6}\left[2 \Delta \delta_{1}-\Delta \delta_{2}-\Delta \delta_{3}\right], \\
& b_{1}=-\sqrt{3} \cos \beta / \cos (\alpha / 2), \quad b_{3}=-\sqrt{3} \cos \delta / \cos (\gamma / 2), \\
& c_{1}=3\left(b_{1}{ }^{2}+1\right),
\end{aligned}
$$

Values of the molecular parameters used in the calculations are given in Table IV. In the case of $\mathrm{CH}_{3} \mathrm{CBr}_{3}$ where no data were available, estimatcs were made from data on related compounds.

Elements of the inverse kinetic energy matrix were evaluated from the expressions given by Decius (24) and transformed into the symmetry coordinate basis by computer. Symmetry force constants obtained for all three molecules are listed in Table $V$ while valence force stretching constants, which can be obtained from the symmetry constants without ambiguity, are given in Table VI. 
TABLE IV

Molecular Parameters for $\mathrm{CH}_{3} \mathrm{CX}_{3}$ Molecules Used in Normal Coordinate Analysis

\begin{tabular}{|c|c|c|c|}
\hline Parameter & $\mathrm{CH}_{3} \mathrm{CF}_{3} \mathbf{a}^{\mathbf{a}}$ & $\mathrm{CH}_{3} \mathrm{CCl}_{3}{ }^{\mathrm{b}}$ & $\mathrm{CH}_{3} \mathrm{CBr}_{8}{ }^{\mathrm{e}}$ \\
\hline C-C dist. $(\AA ̊)$ & 1.512 & 1.550 & 1.540 \\
\hline $\mathrm{C}-\mathrm{X}$ dist. ( $\AA$ ) & 1.344 & 1.767 & 1.940 \\
\hline C-H dist. $(\AA)$ & 1.093 & 1.093 & 1.093 \\
\hline $\mathrm{XCX}$ angle $\left({ }^{\circ}\right)$ & 107.3 & 110.0 & 109.5 \\
\hline $\mathrm{HCH}$ angle $\left({ }^{\circ}\right)$ & 109.5 & 109.5 & 109.5 \\
\hline
\end{tabular}

${ }^{3}$ Ref. (19).

${ }^{\mathrm{b}}$ Ref. (20).

e Estimated from other data.

TABLE V

Symmetry Force Constants for Methyi Haloforms

\begin{tabular}{|c|c|c|c|c|c|c|c|}
\hline & $\mathrm{CH}_{3} \mathrm{CF}_{3}$ & $\mathrm{CH}_{3} \mathrm{CCl}_{3}$ & $\mathrm{CH}_{3} \mathrm{CBr}_{3}$ & & $\mathrm{CH}_{3} \mathrm{CF}_{3}$ & $\mathrm{CH}_{3} \mathrm{CCl}_{3}$ & $\mathrm{CH}_{3} \mathrm{CB}_{\Gamma_{3}}$ \\
\hline$A_{1}$ Species & & & & $E$ Species & & & \\
\hline$F_{1,1}$ & 4.899 & 4.929 & 4.965 & $F_{T .7}$ & 4.896 & 4.770 & 4.750 \\
\hline$F_{2,2}$ & 0.616 & 0.580 & 0.590 & $F_{8,8}$ & 0.539 & 0.538 & 0.525 \\
\hline$F_{3,3}$ & 4.251 & 3.171 & 3.163 & $F_{9,9}$ & 0.557 & 0.649 & 0.590 \\
\hline$F_{4,4}$ & 7.328 & 4.715 & 3.269 & $F_{10,10}$ & 4.571 & 2.366 & 2.820 \\
\hline \multirow[t]{2}{*}{$F_{5,5}$} & 2.005 & 1.369 & 1.529 & $F_{11,11}$ & 1.841 & 1.441 & 1.094 \\
\hline & & & & $F_{12,12}$ & 1.743 & 1.222 & 1.318 \\
\hline$F_{1,2}$ & -0.389 & -0.173 & -0.037 & $F_{7,8}$ & 0.030 & 0.111 & 0.025 \\
\hline$F_{1,3}$ & 0.0 & 0.0 & 0.0 & $F_{7,9}$ & 0.0 & 0.0 & 0.0 \\
\hline$F_{1,4}$ & 0.0 & 0.0 & 0.0 & $F_{7,10}$ & 0.0 & 0.0 & 0.0 \\
\hline$F_{1,5}$ & 0.0 & 0.0 & 0.0 & $F_{7,11}$ & 0.0 & 0.0 & 0.0 \\
\hline$F_{2,3}$ & -0.195 & -0.212 & -0.402 & $F_{7,12}$ & 0.0 & 0.0 & 0.0 \\
\hline$F_{2,4}$ & -0.231 & -0.169 & -0.497 & $F_{8,9}$ & 0.0 & 0.0 & 0.0 \\
\hline$F_{2,5}$ & 0.0 & 0.0 & 0.0 & $F_{8,10}$ & 0.0 & 0.0 & 0.0 \\
\hline$F_{3,4}$ & 1.184 & -0.054 & 0.163 & $F_{8,11}$ & 0.0 & 0.0 & 0.0 \\
\hline$F_{3,5}$ & -0.533 & -0.222 & 0.0 & $F_{8,12}$ & 0.0 & 0.0 & 0.0 \\
\hline \multirow[t]{6}{*}{$F_{4,5}$} & 0.0 & 0.0 & 0.0 & $F_{9,10}$ & 0.0 & 0.0 & 0.0 \\
\hline & & & & $F_{9,11}$ & 0.0 & 0.0 & 0.0 \\
\hline & & & & $F_{9,12}$ & 0.280 & 0.135 & 0.241 \\
\hline & & & & $F_{10,11}$ & 0.306 & 0.0 & 0.0 \\
\hline & & & & $F_{10,12}$ & 0.999 & 0.429 & 1.230 \\
\hline & & & & $F_{11,12}$ & 0.918 & 0.657 & 0.137 \\
\hline
\end{tabular}

Finally, the potential energy distributions among the symmetry coordinates are shown in Tables VII and VIII.

\section{DISCUSSION}

Of the three halides, the data for the fluoride were the most difficult to fit. The cause was not immediately apparent although it can be noted that the $\mathrm{C}-\mathrm{F}$ 
TABLE VI

Valence Stretching Force Constants for Methyl Haloforms (in md/Å)

\begin{tabular}{cccc}
\hline Force constant & $\mathrm{CH}_{3} \mathrm{CF}_{3}$ & $\mathrm{CH}_{3} \mathrm{CCl}_{3}$ & $\mathrm{CH}_{3} \mathrm{CBr}_{3}$ \\
\hline$f_{r}$ & 4.897 & 4.823 & 4.822 \\
$f_{d}$ & 5.490 & 3.149 & 2.970 \\
$f_{R}$ & 4.251 & 3.171 & 3.163 \\
$f_{r r}$ & 0.001 & 0.053 & 0.072 \\
$f_{d d}$ & 0.919 & 0.783 & 0.150 \\
$f_{r d}$ & 0.0 & 0.0 & 0.0 \\
$f_{r d}^{r}$ & 0.0 & 0.0 & 0.0 \\
$f_{r R}$ & 0.0 & 0.0 & 0.0 \\
$f_{d R}$ & 0.684 & -0.031 & 0.094 \\
\hline
\end{tabular}

stretching frequencies and the methyl group rocking and wagging motions occur in the same frequency region and extensive mixing results. The minimum in the hyper-surface explored by the least-squares calculations also appeared to be more shallow and the sides less steep than in the case of the other two halides. Other shallow minima corresponding to alternate force constant solutions were located but were not considered on physical grounds.

The classical motions of $\mathrm{CH}_{3} \mathrm{CF}_{3}$, as shown by the eigenvectors or potential energy matrices (Tables VII and VIII), agree generally with those given by Lafon and Nielsen (6) with the principal exception of the $1282-\mathrm{cm}^{-1}$ frequency which is strongly mixed. Lafon and Nielsen found it to be dominated by the C-C stretch but in the present calculations, it consistently retained a major contribution from the $\mathrm{CF}_{3}$ deformation despite its rather high frequency for this type of motion. The potential energy associated with the $827-\mathrm{cm}^{-1}$ band, on the other hand, was about equally distributed between the $\mathrm{C}-\mathrm{F}$ and $\mathrm{C}-\mathrm{C}$ symmetry coordinates whereas Lafon and Nielsen regarded this band as due principally to $\mathrm{C}-\mathrm{F}$ stretching. These differences serve to emphasize that the form of the normal coordinates is not independent of the nature of the force field used in the analysis, particularly in cases where the frequencies are mixed.

In the case of the other two haloethanes, descriptions of the normal coordinates are relatively straightforward, although mixing occurs in several of the frequencies. It is of some interest to note that the lowest $E$ class frequency in these two cases is predominantly the $\mathrm{CX}_{3}$ asymmetric deformation rather than the $\mathrm{CX}_{3}$ rocking motion, as is the case in the fluoro compound.

The foree constants in Tables V and VI show a few interesting features. In particular, all $\mathrm{C}-\mathrm{C}$ stretching force constants have values significantly less than the value of $4.45 \mathrm{md} / \AA$ reported for ethane (25) also calculated on a symmetry coordinate basis. Structural data show that the $\mathrm{C}-\mathrm{C}$ bond in the chloro compound is measurably $(0.04 \AA)$ longer than in the fluoro case. Although the uncertainty for the $\mathrm{C}-\mathrm{C}$ distance in the chloro compound is larger than one would like, the difference appears real and is in agreement with the force constant trend. 


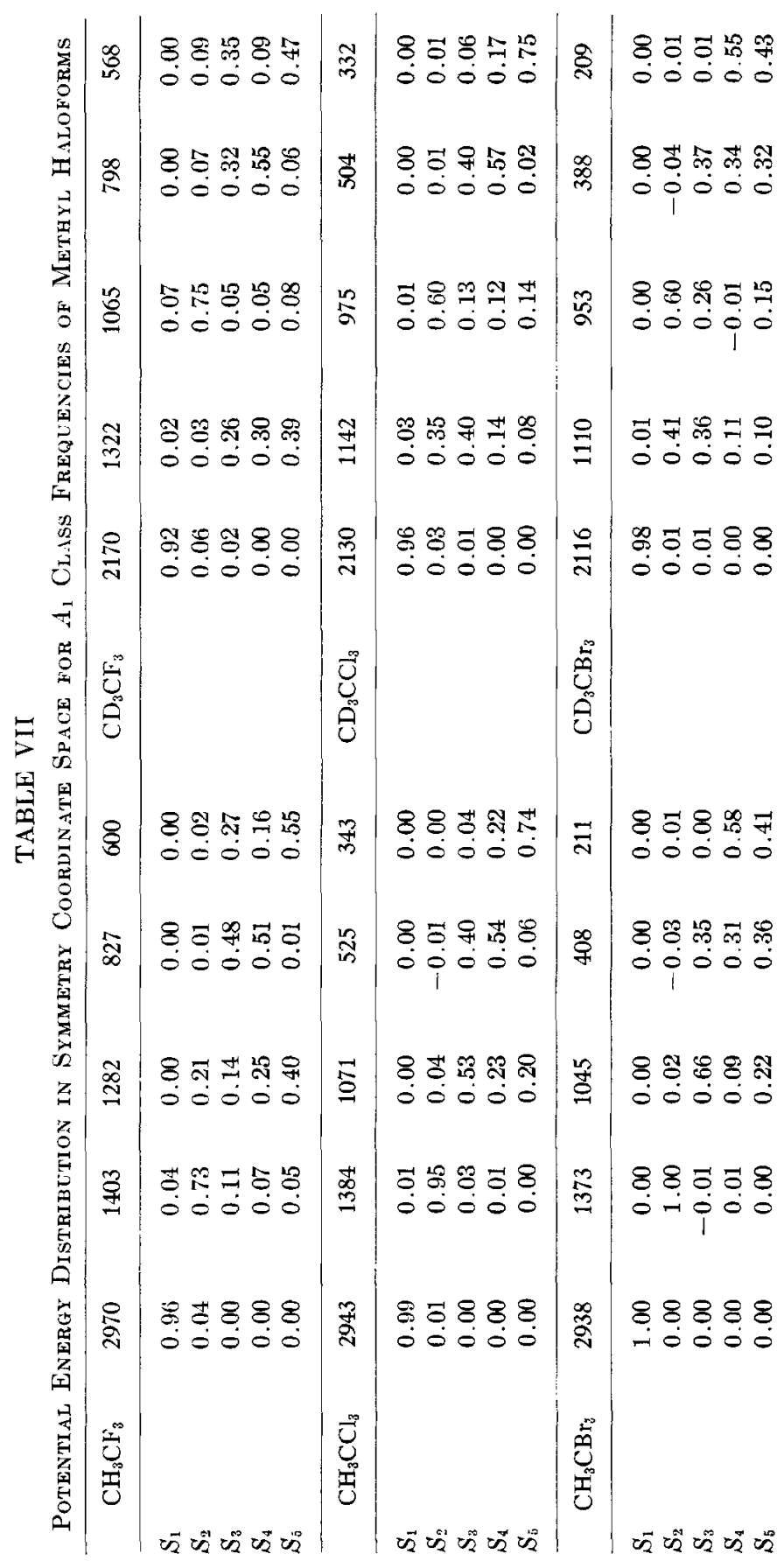




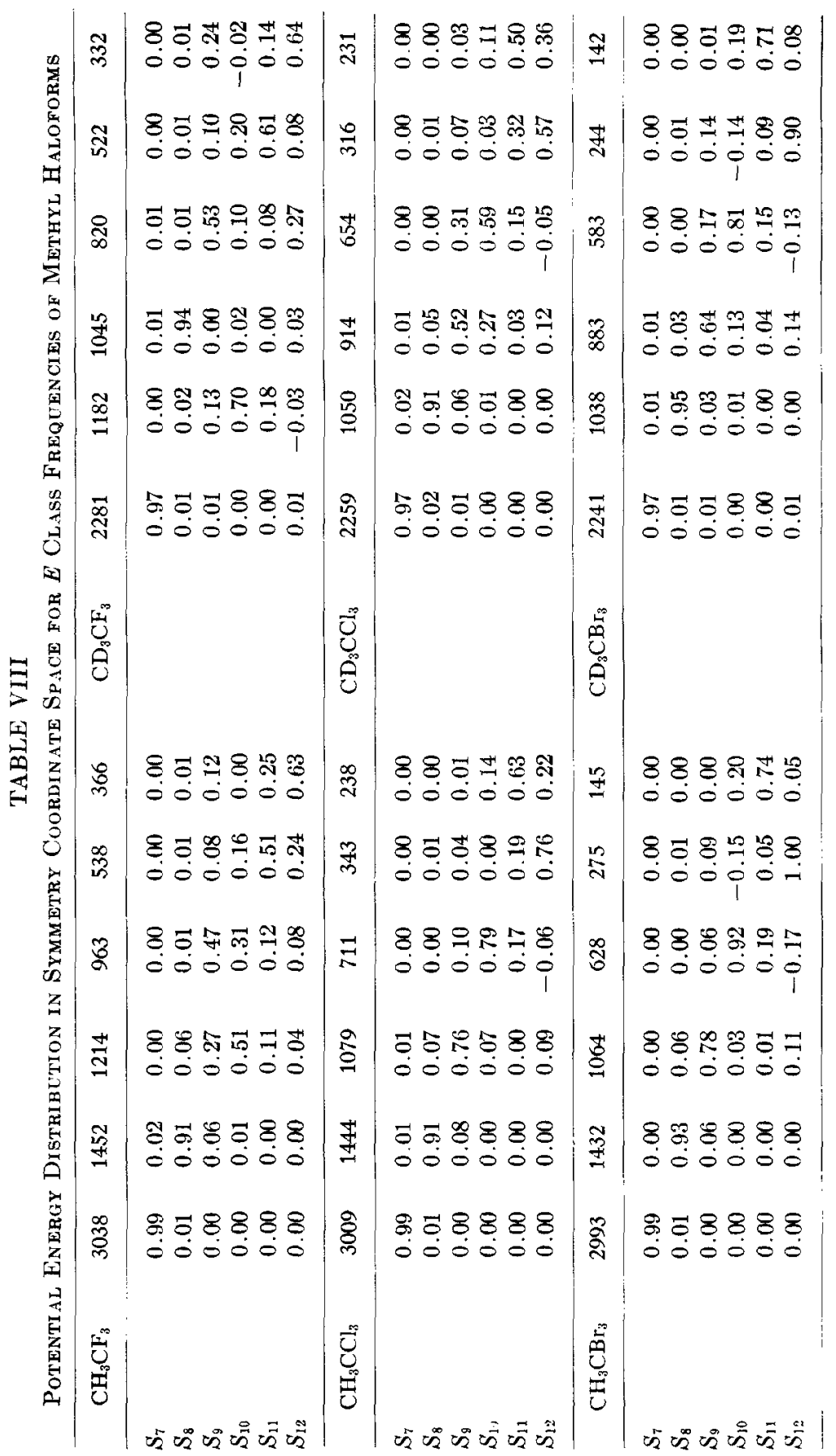


More accurate data for the chloro compound, and data for the bromo compound, would be of considerable interest for comparison with the results of the present calculations. Despite its higher force constant, the $\mathrm{C}-\mathrm{C}$ distance in ethane $(\mathbf{1 . 5 3 4}$ $\AA$ ) is significantly longer than in 1,1,1-trifluoroethane. Clearly, these differences would seem to merit further attention with respect to the electron distributions involved and the particular differences in the halogens.

Received. July 3, 1969

\section{REFERENCES}

1. H. Russell, D. R. V. Golding, And D. M. Yost, I. Amer. Chem. Soc. 66, 16 (1944).

2. H. W. Thompson and R. S. Temple, J. Chem. Soc., London 1948, 1428.

3. H. S. Gutowsky and H. B. Levine, J. Chem. Phys, 18, 1297 (1950).

4. J. R. Nielsen, H. H. Cluaassen, and D. C. Smith, J. Chem. Phys. 18, 1471 (1950).

5. R. D. Cowan, G. Herzberg, And S. P. Sinha, J. Chem. Phys. 18, 1538 (1950).

6. B. Lafon and J. R. Nielsen, J. Mol. Spectrosc. 21, 175 (1966).

7. H. Susi, Ph.D. dissertation, Purdue Univ., 1956; Diss. Abstr. 17, 1913 (1957).

8. P. Venkateswarlu, $J$. Chem. Phys. 19, 298 (1951).

9. M. Z. El-Sabban, A. G. Meister, and F. F. Cleveland, J. Chem. Phys. 19, 855 (1951).

10. K. S. Pitzer and J. L. Hollenberg, J. Amer. Chem. Soc. 75, 2219 (1953).

11. G. Allen and H. J. Bernstein, Can. J. Chem. 32, 1124 (1954).

12. J. C. Evans and H. J. Bernstein, Can. J. Chem. 33, 1746 (1955).

19. H. P. Bucker and J. R. Nielsen, J. Mol. Spectrosc. 11, 243 (1963).

14. M. Randic and I. M. Mills, $J$. Chem. Phys. 31, 1681 (1959).

15. A. L. Henne and M. W. Renold, J. Amer. Chem. Soc. 58, 889 (1936).

16. J. E. Francis and L. C. Leitch, Can. J. Chem. 35, 348 (1957).

17. W. TAYlor, J. Chem. Soc., London 1935, 1514.

18. G. L. Vidale and R. C. Taylor, J. Amer. Chem. Soc. 78, 294 (1956).

19. R. H. Schwendeman, Ph.D. dissertation, The University of Michigan, 1958; Diss. Abstr. 18, 1645 (1958); c.f. also, L. E. Sutton, 1965, "Interatomic Distances, Suppl., p. M77s, Chem. Soc., London.

20. S. N. Ghosh, R. Trambarulo, and W. Gordy, J. Chem. Phys. 20,605 (1952).

21. J. Overend Ann J. R. Scherer, J. Chem. Phys. 32, 1289 (1960).

22. J. Aldous And I. M. Mills, Spectrochim. Acta 18, 1073 (1963).

23. E. A. Clark and A. Weber, J. Chem. Phys. 45, 1759 (1966).

24. J. C. Decius, J. Chem. Phys. 16, 1025 (1948).

25. J. L. Duncan, Spectrochim. Acta 20, 1197 (1964). 